\title{
TRANSPLANTE RENAL: ORIENTAÇÕES DE ENFERMAGEM PARA ALTA HOSPITALAR
}

\author{
Kidney transplantation: guidelines of nursing in the hospital discharge
}

Gilvana de Campos Dalponte, Fernanda Silva de Souza Rodrigues

\begin{abstract}
RESUMO
Introdução: O transplante renal é um procedimento usado como tratamento cirúrgico em pacientes portadores de doença renal em estágio terminal. Objetivo: Realizar o levantamento das principais orientações encontradas na literatura e que precisam ser repassadas pela enfermagem aos pacientes transplantados de rim, no momento da alta hospitalar. Método: Utilizou-se o método de revisão integrativa de literatura da produção científica nacional e internacional na área de transplantes, através de investigação nas bases de dados da Biblioteca Virtual de Saúde (BVS), cuja amostra foi de vinte publicações. Resultado: A análise dos estudos possibilitou relacionar as principais demandas de autocuidado necessárias ao paciente transplantado. Conclusão: Ficou clara a relevância das orientações de alta dadas pela enfermeira, bem como o entendimento do paciente acerca dessas orientações para adesão ao tratamento e sucesso do transplante.
\end{abstract}

Keywords: Transplante Renal; Enfermagem; Alta Hospitalar; Qualidade de Vida; Autocuidado.

Instituição:

Departamento de Enfermagem da Universidade Feevale RS Porto Alegre/RS

\section{Correspondência:}

Gilvana de Campos Dalponte

End.: Rua Congonhas, 95/104, CEP 91225130, Porto Alegre/RS

Tel: (51) 9162-1742

E-mail: gilvanadalponte@terra.com.br
Aceito em: 25/03/2014

\section{INTRODUÇÃO}

O transplante renal é um procedimento usado como tratamento cirúrgico em pacientes portadores de doença renal em estágio terminal (DRET). É vastamente aceito como o melhor tratamento para esses pacientes, assegurando uma taxa de sobrevivência e qualidade de vida relativamente maiores em relação aos que permanecem em terapia dialítica. ${ }^{1}$

O enfermeiro possui um importante papel como orientador educacional em unidades de transplante renal, promovendo a adesão ao tratamento por parte do receptor e realizando a orientação educacional de enfermagem. ${ }^{2}$ As orientações de alta no pós-transplante têm como finalidade: promover o autocuidado do paciente, evitando complicações, como doenças infecciosas e rejeição do enxerto, proporcionar a aderência à terapia imunossupressora, bem como o conhecimento dos efeitos adversos trazidos por ela. ${ }^{3}$

A palavra "orientar" origina-se do latim "oriri", que significa "indicar o rumo, a direção", "aconselhar". ${ }^{4}$ 
Um dos mais importantes papéis do enfermeiro durante a alta hospitalar do paciente transplantado é o da orientação, ou seja, direcionar, ensinar ao paciente e seus familiares como realizar o autocuidado póstransplante.

Existe uma relação direta entre a falta de conhecimento do regime terapêutico e a perda do enxerto. ${ }^{2,3,5-7}$ Para o êxito do transplante, é necessário que o paciente adote um estilo de vida diferenciado em relação à medicação, à higiene e aos cuidados com a saúde. ${ }^{8}$ Assim, é desejável que o enfermeiro conheça o seu estilo de vida para que, através das orientações de alta, possa ensiná-lo a modificar hábitos que venham a prejudicar o bom funcionamento do enxerto. ${ }^{9}$

Dessa forma, as orientações de enfermagem ao paciente transplantado no momento da alta hospitalar devem ser feitas de maneira clara e simples, compreensível para qualquer nível sociocultural, de forma a esclarecer dúvidas e promover o autocuidado, com o intuito de ajudá-lo na adaptação às mudanças que ocorrerão em sua vida. ${ }^{2,3}$

Diante do exposto, identificou-se a necessidade de aprofundar o conhecimento a respeito do assunto, a fim de percorrer as orientações de autocuidado que precisam ser realizadas no momento da alta hospitalar.

\section{OBJETIVO}

Este artigo tem como objetivo descrever as orientações de autocuidado que precisam ser realizadas no paciente transplantado renal no momento da alta hospitalar.

\section{MATERIAL E MÉTODO}

Trata-se de um estudo descritivo de revisão integrativa da produção científica nacional e internacional na área de transplantes, relacionado às orientações de alta hospitalar para pacientes transplantados de rim.

A pergunta norteadora da revisão constitui-se em: quais são as orientações que precisam ser realizadas ao paciente transplantado de rim no planejamento de alta hospitalar?

A pesquisa foi feita através de investigação nas bases de dados da Biblioteca Virtual em Saúde (BVS), utilizando-se os descritores transplante renal, enfermagem, alta hospitalar, qualidade de vida e autocuidado. O período de coleta e análise dos dados ocorreu entre os meses de outubro de 2013 e janeiro de 2014 .

Foram critérios de inclusão os artigos que retratassem os cuidados a serem realizados pelos pacientes após o transplante renal e os artigos disponíveis (na íntegra), nos idiomas inglês, espanhol e português, sem recorte temporal delimitado.
Realizou-se a leitura do título, resumo e os resultados encontrados nos artigos, a fim de selecionar, de forma mais assertiva, os que respondessem ao objetivo deste estudo.

Foi selecionada uma amostra final de 20 artigos submetidos à técnica de análise de conteúdo, alcançada através de leitura crítica e posterior agrupamento dos achados.

\section{RESULTADO E DISCUSSÃO}

A análise dos textos permitiu a identificação de 20 artigos. Desses, cinco foram escritos por enfermeiros, 13 por médicos, um por enfermeiro e médico, e um por dentista. Isso demonstra carência de publicações nessa classe, que atua junto a esses pacientes, 24 horas por dia, durante a internação, e que está diretamente envolvida no processo de alta hospitalar.

As publicações evidenciaram cuidados referentes a vários aspectos, que foram classificados, agrupados e apresentados sob a forma de tópicos para melhor discussão.

\section{Conhecer os medicamentos e fazer uso de forma correta}

O paciente transplantado corre o risco de rejeição, necessitando fazer uso de medicamentos imunossupressores por toda a vida. É importante o enfermeiro ressaltar nas orientações de alta as informações sobre a medicação, além do horário, finalidade e os seus efeitos adversos. ${ }^{10}$

As principais causas da não aderência ao tratamento medicamentoso são: esquecimento, cansaço, aparecimento dos efeitos colaterais e, no caso de crianças transplantadas, o sabor e o tamanho dos fármacos. ${ }^{5,7} \mathrm{Da}$ mesma forma, é fato que o abandono do tratamento relaciona-se ao baixo nível socioeconômico, às famílias desestruturadas, à idade, à ausência de apoio familiar e à baixa autoestima. ${ }^{5,7}$

\section{Reconhecer os efeitos adversos dos imunossupressores}

Deve-se orientar sobre os benefícios dos imunossupressores, bem como seus efeitos adversos, para que o paciente possa lidar com os eventos indesejáveis que, muitas vezes, são inevitáveis. Ao fazer uso de imunossupressores, o paciente poderá apresentar efeitos colaterais, como: problemas na visão, aumento do apetite, ganho de peso, osteoporose, predisposição para fraturas e necrose avascular da cabeça do fêmur, disfunção sexual, hipertensão, hiperlipidemia, Diabettes Melittus, doenças ulcerosas, acne ou pelos faciais, diarreia, suscebilidade a infecções fúngicas, virais e bacterianas, doenças malignas, dentre outros..$^{1,2,5,8,10,11}$

Os problemas mais frequentes causados pelos efeitos colaterais das drogas imunossupressoras são: o aumento do apetite, seguido pelo ganho de peso. ${ }^{8}$ Já a hipertensão arterial sistêmica ocorre em, aproximadamente, $80 \%$ dos pacientes receptores de transplante renal, em uso de inibidores de calcineurina. ${ }^{12}$ 


\section{Não utilizar medicamentos sem a receita do médico nefrologista}

O paciente deve ser informado que nenhuma alteração ou introdução de medicação deve ser feita sem o conhecimento da equipe de transplantes.

É importante que o paciente tenha esse conhecimento, devido ao fato de que certos medicamentos comumente usados interferem nos níveis plasmáticos de inibidores da calcineurina, como o tacrolimus, por exemplo. ${ }^{13}$ Existem medicamentos como a metoclopramida e alguns tipos de antibióticos e antifúngicos, que podem, potencialmente, aumentar o risco de nefrotoxicicidade, se administrados juntamente com os imunossupressores. ${ }^{13}$

\section{Utilizar protetor solar e evitar exposição ao sol}

O risco de tumores malignos na pele torna-se maior em pacientes transplantados, devido ao uso de imunossupressores. ${ }^{11}$ As doenças malignas apresentam um comportamento biológico mais agressivo, em longo prazo, durante a imunossupressão. A incidência de tumores malignos de pele é superior em pacientes após o transplante de órgãos, em comparação com a população geral. ${ }^{11}$

O paciente deve ser informado que o banho de sol precisa ser evitado durante a terapia imunossupressora. A pele exposta ao sol precisa ser protegida com uma loção com fator de proteção alta (no mínimo $30 \mathrm{SPF}$ ). Assim, quanto maior o fator de proteção, melhor. ${ }^{10,11}$

\section{Ingerir dois litros de água por dia}

Durante o período de diálise, a maioria dos pacientes com doença renal terminal não urinam, o que leva à inatividade da bexiga e a alterações atróficas das paredes da bexiga. Após o transplante, a produção de urina é restaurada imediatamente ou em poucos dias pelo novo rim. Entretanto, a adaptação do trato urinário baixo, como a adaptação da bexiga e a normalização da capacidade e acomodação vesical e dos parâmetros urodinâmicos, é conseguida até seis meses após o transplante. ${ }^{14}$ Dessa forma, os pacientes devem ser instruídos a tomar, no mínimo, dois litros de água por dia, para facilitar a preservação da função renal e readaptação do trato urinário baixo. ${ }^{14}$

\section{Conhecer os sinais e sintomas de rejeição e comunicar ao médico (caso apareçam)}

A rejeição crônica do enxerto pode ocorrer pelo resultado de diferentes agressões a ele, que são mediadas por mecanismos imunológiᄀcos e não imunológicos. ${ }^{12}$

Os fatores imunológicos estão relacionados à aloimunidade do receptor, ou seja, à resposta imune que o organismo do receptor adquire contra as células do enxerto. Já os fatores não imunológicos dizem respeito mais diretamente à qualidade do órgão implantado, aos insultos que o órgão foi submetido antes do transplante, às agressões no pós-transplante, como o uso de drogas nefrotóxicas, e a fatores relacionados ao receptor (presentes antes do transplante) ou que, posteriormente, possam se desenvolver, como diabettes mellitus, hipertensão e dislipidemias, por exemplo. ${ }^{12}$ Esses fatores desencadeiam a doença crônica do enxerto renal, evidenciada pelos sintomas de dor ou inchaço sobre o rim transplantado, febre acima de 37 graus, diminuição da urina, ganho de peso, inchaço de pálpebras, mãos e pés, dor ao urinar, aumento na pressão sanguínea e tosse ou falta de ar. ${ }^{6,12,15} \mathrm{O}$ enfermeiro deve explicar ao paciente que esses sintomas podem aparecer e, caso isso ocorra, ele precisa entrar em contato com a equipe de transplantes, imediatamente..$^{9,15}$

\section{Realizar atividade física regular}

A atividade física em pacientes transplantados está relacionada à melhora cardiorrespiratória, à força muscular, ao funcionamento físico e à qualidade de vida, proporcionando a redução dos efeitos adversos associados à terapia imunossupressora, incluindo ganho de peso e reduções na osteoporose e sarcopenia. ${ }^{16-18}$ Há fortes evidências de que a atividade física esteja relacionada com a função do enxerto, ou seja, a rejeição pode ser prevenida pela realização de exercícios físicos. ${ }^{12,18}$ Nos primeiros meses póstransplante, além da adaptação do novo rim ao organismo, ocorre a cicatrização da ferida cirúrgica, e o paciente deve ser orientado a não realizar atividades que produzam ou aumentem a dor no local da cirurgia, como levantar, empurrar ou puxar objetos grandes ou pesados. ${ }^{13,17}$ Caminhadas e natação são algumas atividades indicadas para pacientes transplantados. Entretanto, esportes mais traumáticos, que provoquem choque na região abdominal (como o futebol), devem ser evitados. ${ }^{17}$ Também, orienta-se a diminuir as atividades, caso o paciente esteja tratando alguma infecção. ${ }^{17}$ Os pacientes podem retomar suas atividades diárias após oito semanas de transplante, mas deve-se aconselhar que não faça trabalho pesado e vigoroso durante os primeiros seis meses pós-transplante. . $^{13,17}$

\section{Realizar dieta e cuidados com alimentação}

Os imunossupressores têm como principais efeitos colaterais o aumento do apetite, hiperlipidemia, hiperglicemia e hipertensão. ${ }^{8,13,19}$ Assim, para evitar os efeitos colaterais das drogas imunossupressoras, modificações dietéticas devem ser implementadas após o transplante renal. ${ }^{19}$

O ganho de peso é um sério problema em longo prazo para os transplantados renais, o que leva à necessidade da realização de uma dieta hipossódica com pouca gordura e baixo açúcar. 8,10,13,19 Da mesma forma, ocorre com o metabolismo da glicose, onde o paciente pode desenvolver Diabetes Mellitus relacionada ao início da corticoterapia. ${ }^{19}$ 
Sendo assim, os pacientes devem ser orientados precocemente sobre os efeitos colaterais da terapia imunossupressora e encorajados a reduzir a ingestão calórica, bem como iniciar um programa gradual de atividade física para manter o gasto energético adequado. ${ }^{19}$

\section{Adotar medidas de controle à infecção}

A infecção pós-transplante é uma das principais causas de morbidade e mortalidade, juntamente com a rejeição do enxerto. ${ }^{13,14} \mathrm{O}$ paciente imunodeprimido pode ser acometido por infecções do tipo bacterianas, virais e fúngicas. Algumas infecções são o resultado de exposições da comunidade. Enquanto umas são transmitidas com o enxerto (ex citomegalovírus, vírus Epstein-Barr), outras são o resultado das exposições mais distantes, reativados no ambiente de imunossupressão, como a catapora e a herpes varicela zoster. $^{14}$

Para evitar infecções, o paciente deve ser orientado sobre a adoção de medidas de prevenção, como:

\section{Evitar aglomerações e contato com pessoas que possam estar doentes}

Pessoas que apresentem sintomas, tais como resfriado, diarreia ou febre devem evitar entrar em contato com pacientes imunodeprimidos. Da mesma forma, quem mora na mesma casa ou cuida de pessoa com imunodepressão pode, através do contato inter-humano e/ou fômites (toalhas e roupas), transmitir infecções ao paciente imunodeprimido.9,13,20 Para isso, medidas de prevenção à infecção devem ser ensinadas ao paciente e seus familiares, como lavar as mãos frequentemente com água e sabão e usar álcool gel $70 \%$ diversas vezes ao dia, evitar ambientes fechados e com aglomeração de pessoas, não compartilhar alimentos, copos, toalhas e objetos de uso pessoal. ${ }^{20}$

\section{Realizar higiene oral}

O uso de Ciclosporina em pacientes pós-transplantados pode desencadear efeitos colaterais na cavidade oral, como língua saburrosa, aftas e hiperplasia gengival. Entretanto, também poderão ocorrer infecções oportunistas por fungos e vírus por meio da cavidade oral. ${ }^{21}$

Dessa forma, o cuidado com a saúde da boca, através da higiene oral, deve ser enfatizado após o transplante. O paciente deverá fazer o uso de escovas de dente com cerdas macias para evitar lesões e realizar a limpeza da língua como coadjuvante à escovação dentária, justificada pelo fato da língua representar um dos principais nichos microbianos da cavidade oral. ${ }^{21,22}$ As doenças gengivais e as cáries devem ser tratadas antes do transplante, de forma a evitar futuras complicações orais associadas à imunossupressão. ${ }^{22}$

\section{Realizar higiene corporal e ambiental}

Pacientes imunodeprimidos são frequentemente acometidos por infecções parasitárias. ${ }^{23}$ Essas infecções estão relacionadas à condição socioeconômica e higiênicosanitária do paciente. A transmissão é por via fecal-oral, por ingestão de água e alimentos contaminados pelos oocistos de parasitas, de pessoa a pessoa, por inalação ou por autoinfecção. ${ }^{24}$

Para prevenir essa condição, o paciente precisa adquirir o hábito de tomar banho diariamente e manter as mãos sempre limpas, as unhas cortadas e não andar descalço. ${ }^{24} \mathrm{~A}$ caixa de água deve ser limpa periodicamente; fazer uso de água filtrada - o filtro deve ser trocado conforme as instruções do fabricante; os alimentos devem ser bem lavados e cozidos. ${ }^{24}$

O paciente transplantado também deverá ser orientado a evitar ambientes poluídos, e ainda tudo que acumule poeira dentro de casa, como carpetes e tapetes, a fim de evitar infecção por fungos, como o aspergillus, por exemplo. ${ }^{25,26}$ Orienta-se manter a casa limpa, passar o aspirador e retirar a poeira dos móveis uma vez ao dia. ${ }^{26}$

Deve-se destacar ao paciente a relevância da higiene corporal e ambiental como um dos fatores indispensáveis para a prevenção das infecções. ${ }^{23}$

\section{Não realizar vacinação nos três primeiros meses após o transplante}

Quando uma vacina é administrada em pessoas imunocompetentes, por serem compostas de vírus ou bactérias vivos atenuados, infectam os pacientes e os induzem a formar anticorpos, os quais os protegerão de micro-organismos mais virulentos. Essas vacinas vivas são seguras para indivíduos saudáveis. Entretanto, por produzirem uma pequena infecção em pessoas nas quais o sistema imune esteja prejudicado, como os pacientes que recebem transplante, elas podem provocar uma infecção incontrolável. ${ }^{27}$

Assim, deve ser recomendado que nenhuma vacina seja administrada em pacientes que recebem altas doses de imunossupressores, sendo indicada a sua administração anterior ao transplante, ou seja, o esquema vacinal deve ser iniciado logo após a inclusão do indivíduo na lista de espera. ${ }^{13}$ Caso o transplante ocorra em crianças muito jovens, o calendário vacinal pode ser adiado para após o transplante..$^{13}$

É necessário que as doses dos imunossupressores sejam reduzidas (o que corresponde, em média, ao período de três a seis meses após o transplante), para então retomar a vacinação com vacinas inativadas. ${ }^{13}$

\section{Evitar contato com criança vacinada contra poliomielite}

A vacina oral contra a pólio (VOP) é composta por vírus vivo, sendo contraindicada em pacientes imunocomprometidos e 
seus contatantes domiciliares. ${ }^{9}$ Quando houver indicação de vacinação contra pólio em pacientes imunocomprometidos, seus familiares ou pessoas de contato próximo, o paciente deve receber a vacina pólio inativada (VIP). Quando há o uso inadvertido da vacina oral nos contatantes, recomenda-se evitar o contato com o paciente por, aproximadamente, um mês. ${ }^{27}$

Já as vacinas antiinfluenza (gripe) e pneumocócica são indicadas nas idades apropriadas para os contatos domiciliares de pessoas imunocomprometidas, a fim de ajudar a prevenir a propagação de infecções entre esses pacientes de alto risco. ${ }^{13}$

\section{CONCLUSÃO}

No presente estudo, foram abordadas as principais orientações de autocuidado que devem ser realizadas pelo paciente transplantado renal após a sua alta hospitalar. Verificou-se que o paciente pós-transplante renal necessita ser muito bem orientado antes da alta hospitalar, para que o procedimento tenha bom resultado.

Por esse motivo, o papel educador do enfermeiro que atua junto ao paciente é de fundamental importância, já que estará acompanhando o paciente em todas as etapas do processo, inclusive na preparação para a alta hospitalar.
A alta hospitalar do paciente deve ser muito bem planejada, pois a revisão da literatura mostrou que são muitos os cuidados necessários para que o resultado do transplante seja positivo, e ele precisa compreendê-los para ter condições de executálos em seu domicílio. O enfermeiro deve estar atento e incluir o familiar nesse processo para poder auxiliar o paciente.

Dentre os cuidados na pós-alta hospitalar encontrados na literatura, estão: o uso correto dos medicamentos prescritos pelo médico, o reconhecimento dos efeitos adversos dos imunossupressores, a não utilização de outros medicamentos que não estejam prescritos pelo médico, a não exposição solar (utilizando protetor sempre), a realização de uma ingestão hídrica adequada; o conhecimento dos sinais e sintomas de rejeição e a comunicação com a equipe de transplantes (caso apareçam), a realização de atividade física regular a adequação da dieta e medidas rigorosas de controle à infecção.

Após a relação dos achados nesta revisão integrativa, fica clara a relevância das orientações de alta, bem como o entendimento do paciente acerca destas orientações para uma ótima adesão ao tratamento e sucesso do transplante.

O papel do enfermeiro em transplantes renal, precisa ser mais discutido e divulgado diante da importância da sua atuação nesta área, visto que foram poucos os artigos disponíveis na literatura sobre as orientações de alta hospitalar em indivíduos transplantados de rim.

\section{ABSTRACT}

Introduction: Kidney transplantation is a procedure used as surgical treatment in patients with end-stage renal disease. Purpose: To survey the main guidelines found in the literature which needs to be passed by the nursing to kidney transplanted patients at the time of the hospital discharge. Method: It was used the integrative literature review method of the national and international scientific production in the transplantation area by researching on the Virtual Health Library (VHL) databases by sampling twenty publications. Results: The analysis of the studies enabled the main demands relate to self-care needed for transplant patients. Conclusion: It was clear the high relevance of the guidelines given by the nurse and the patient's understanding about these guidelines for treatment adherence and successful transplantation.

Keywords: Kidney Transplantation; Nursing; Patient Discharge; Quality of Life; Self Care. 


\section{REFERÊNCIAS}

1- Garcia GG, Harden P, Chapman J. O papel global do transplante renal. J. Bras. Nefrol. 2012;34(1):1-7

2 - Furtado AMO, De Souza SROS, Oliveira BL, Garcia CN. $O$ enfermeiro assistencial e educador em uma unidade de transplante renal: uma questão desafiadora. Enferm. Glob. 2012 Jul;11(27):346-50.

3 - Rubio FM, Montaña EV. El processo de enfermería de autocuidado genera mayor adherencia al tratamiento en transplante renal. Repert.med.cir. 2010;19(1):14-17.

4 - Ferreira ABH. Mini Aurélio. 6th ed. Curitiba: Editora Positivo; 2007.

5 - García PC, Montero AC, Amblás RT. Cumplimiento del tratamiento en el trasplante renal pediátrico. Rev Soc Esp Enferm Nefrol. 2010 Set;13(3):173-9.

6 - Peña FR, Echaniz SC, Mota MPG, Requejo AD, Arrien LA, García ARM et al. Problemas de enfermería en el trasplante a pacientes añosos. Rev Soc Esp Enferm Nefrol. 2009 Dez;12(4): 34-39.

7 - Orofino L, Marcén R, Quereda C, Burgos J, Ortuño J. Adhesión al tratamento del paciente transplantado renal. Nefrologia. 1994;14(3):329-32.

8 - Lira ALBC, Lopes MVO. Pacientes transplantados renais: análise de associação dos diagnósticos de enfermagem. Rev. Gaúcha Enferm. 2010 Mar;31(1):108-14.

9- Ferrero HS. Cuidados de enfermería en el trasplante renal basados em el modelo de Virginia Henderson - BISEDEN. 1996(1):17-1

10- Castro MCC. Kidney Transplant. Nursing. 2009;39(3):33.

11- Schrem H, Barg-Hock H, Strassburg CP, Schwarz A, Klempnauer J. Aftercare for Patients With Transplanted Organs. Dtsch Arztebl International. 2009;106(9):148-56.

12 - Manfro RC. Manejo da doença crônica do enxerto renal. J. Bras. Nefrol. 2011 Dez;33(4):485-92.

13 - Lau KK, Giglia L, Chan H, Chan AK. Management of children after renal transplantation: Highlights for general pediatricians. Zhongguo Dang Dai Er Ke Za Zhi. 2012 Feb;14(2):81-8.

14 - Cukuranovic J, Ugrenovic S, Jovanovic I, Visnjic M, Stefanovic V. Viral Infection in Renal Transplant Recipients. The Scientific World Journal. ScientificWorldJournal. 2012:820621

15 - Kidney Handbook. Your kidney Transplant: A basic overview of your daily, healthcare, medications, and monitoring. Virginia Commonwealth University Health System. 2002; p23-31. Disponível em: http://www. vcuhealth.org/transplant/docs/post $\% 20$ op $\% 20$ kidney $\% 20$ booklet.pdf

16 - Diseth TH, Tangeraas T, Reinfjell T, Bjerre A. Kidney transplantation in childhood: mental health and quality of life of children and caregivers. Pediatr Nephrol. 2011 Out;26(10):1881-92.

17 - Alves D, André R. Prescrição e benefícios da atividade física em transplantados. Grupo de Estudos Avançados em Saúde e Exercícios - GEASE. 2003 Jun. Disponível em: http://www.gease.pro.br/artigo_visualizar.php?id=94.
18 - Gordon EJ, Prohaska TR, Gallant MP, Sehgal AR, Strogatz D, Conti D et al. Prevalence and Determinants of Physical Activity and Fluid Intake in Kidney Transplant Recipients . Clin Transplant. 2010 MaiJun;24(3):E69-81.

9 - Papini H, Santana R, Ajzen H, Ramos OL, Pestana JOM. Alterações metabólicas e nutricionais e orientação dietética para pacientes submetidos a transplante renal. J. Bras. Nefrol. 1996 Dez;18(4):356-69.

20 - Governo do estado do RS. Centro estadual de vigilância e saúde. Medidas de prevenção e precaução para a comunidade. 2009. [acesso em 2012 Dez 21]. Disponível em: http://www.saude. rs.gov.br/upload/20120611095018medidas_de_ prevencao_e_precaucao_para_a_comunidade. pdf.

21 - García ER, Padilla AM. Efecto del micofenolato de mofetilo y azatioprina sobre la hiperplasia gingival asociada al uso de ciclosporina $A$ en pacientes con trasplante renal. Nefrología. 2009;29(5):474-78.

22 - Gondim LAM. Avaliação clínica e microbiológica das condições de saúde oral dos receptores de transplante renal do Hospital Universitário Onofre Lopes [dissertação na internet]. Natal: Universidade Federal do Rio Grande do Norte. 2001. [acesso em 2012 Dez 08]. Disponível em: http://repositorio.ufrn.br:8080/jspui/ bitstream/1/9107/1/LibiaAMG.pdf

23 - Sousa SR, Galante NZ, Barbosa DA, Pestana JO. Medina. Incidência e fatores de risco para complicações infecciosas no primeiro ano após o transplante renal. J. Bras. Nefrol. 2010 Mar;32(1):77-84.

24 - Paul MM. Prevenção de parasitoses intestinais [trabalho de conclusão de curso]. Rio de Janeiro: Escola de Saúde do Exército, 2008. [acesso em 2012 Dez 15]. Disponível em: http://www.essex.ensino. eb.br/doc/PDF/PCC_2008_CFO_PDF/CD74\%20 1\%BA\%20Ten\%20AI\%20MARIAN̄A\%20MONDIN\%20 PAUL.pdf

25 - Neto MM, Muglia V, Batista MEPN, Pisi TM, Saber LTS, Ferraz AS et al. Infecção por fungos e Transplante Renal: Análise nos primeiros 500 pacientes transplantados no Hospital das Clínicas da Faculdade de Medicina de Ribeirão Preto - USP. J. Bras. Nefrol. [periódico na Internet]. 1995. [acesso em 2012 out 15]. 17(3): 162-170. Disponível em: http://www.jbn. org.br/audiencia_pdf.asp?aid2=1012\&nomeArqui vo=17-03-08.pdf.

26 - Prefeitura Municipal de Campos dos Goytacazes. Programa educar para não adoecer. Instruções para controle de poeira no meio ambiente. 2010. [acesso em 2012 Nov 13]. Disponível em: http://www.hgg.rj.gov.br/ setores/integrar_humanizar/arquivos/pena/controlepo. pdf

27 - Luz KR, Souza DCC, Ciconelli RM. Vacinação em pacientes imunossuprimidos e com doenças reumatológicas auto-imunes. Rev. Bras. Reumatol. 2007 Abr;47(2):106-13. 